\title{
DEVELOPMENT A SIMPLE LABORATORY UNIT FOR CALIBRATION AND TESTING SEED DRILLS
}

Bahnasy, A. F.; A. M. Aboukarima; M. E. Morsi and S. N. Abd El Halim.

Agric. Eng. Res. Inst., Agric. Res. Center, Ministry of Agric. and Land Reclamation.

\begin{abstract}
A simple laboratory unit for calibration and testing seed drills was developed. It was consisted of iron frame, variable speed electric motor and two support rolls covered with rubber to control the ground wheel revaluations of the seed drill. The developed unit was checked by operating Colorado seed drill under different treatments, which included three simulated ground wheel speeds and three inflation pressures of the ground wheel. The outputs which affected by these treatments were application rate of wheat seeds and coefficient of variation. The results showed that, the developed unit had ability to move the ground wheel with stable revaluations. Average of the coefficient of variation of weight of the wheat seeds deposited from 21 tubes varied between 4.75 to $7.63 \%$. The relative ease with which the unit is adjusted in the laboratory suits the technical know how of the factors affected on the imported or locally made seed drills could be studied.
\end{abstract}

Keywords: Seed drill, testing, calibration.

\section{INTRODUCTION}

The primary objective of any planting operation is to establish an optimum plant population and plant spacing, the ultimate goal being to obtain the maximum net return per hectare. Population and spacing requirements are influenced by factors such as the kind of crop, the type of soil, the fertility level of the soil, available soil moisture, and the effect of plant and row spacing upon the cost and convenience of operations such as thinning, weed control, cultivation, and harvesting (Kepner et al., 1980). Amount of seeds in rows is an important factor in crop production, which can affect growth and yield and this to a great extent depends on the performance of the metering mechanism of the seed drill/planter (Raheman and Singh, 2003). Therefore, proper calibration of a seed drill/planter is an essential job for satisfactory germination in the field. The variation seeding rate from that given in the operator's manual may be due to a number of factors given as follows: traveling speed, tire inflation, seeder drive wheel slippage, differences in the seeds (Hendawy, 1996).

Testing of a seed drill in the field is costly and very difficult. Thus, a suitable laboratory setup is therefore needed to calibrate and test of a seed drill to indicate its performance in easy way. In literature there are different attempts to build such setups for that purposes by which the operator can know the performance of the seed drill. However, test a seed drill including different items, such as seed spacing uniformity, etc. A coefficient of variation (CV) was listed to reflect the sensitivity of the experiment since it was subject to environmental effects beyond the control of the researchers. 
Bahnasy, A. F. et al.

Boydas and Turgut (2007) mentioned that CV in seed flow evenness for seed drill could be determined in a laboratory experiment. The simulated ground speed was $6.5 \mathrm{~km} / \mathrm{h}$. A coefficient of variation of less than $10 \%$ is generally considered acceptable for field research where climate and soil variations can influence experimental results (Ess et al., 2005). PAMI (1978) reported that $\mathrm{CV}$ is commonly used to describe the variation of application rate among individual seed tubes. An accepted variation for grain application is a CV value not greater than $15 \%$. If the $\mathrm{CV}$ is less than $15 \%$, seeding is quite uniform whereas if the $\mathrm{CV}$ is much greater than $15 \%$, the variation among individual seed tubes is excessive. However, CV values between $10 \%$ and $20 \%$ are considered "acceptable," the values between $5 \%$ and $10 \%$ are "good," and the values less than $5 \%$ are "very good" (Guler, 2005).

Performance of a seeder has remarkable influences on cost and yield of agricultural products and especially its seeding uniformity is a crucial index in estimation of a seeder's quality ( $\mathrm{Li}$ and Lin, 2006). Method of seed distribution and accuracy of seed placement can have significant effects on stand establishment and crop yield for most crops (Siemens et al., 2007). Nielsen (1995) concluded that a yield loss of at least $78 \mathrm{~kg}$ seed $/ \mathrm{ha}$ per $\mathrm{km} / \mathrm{h}$ speed increase occurs in the speed range of 6.4 to $11.3 \mathrm{~km} / \mathrm{h}$.

Babeir and Al Suhaibani (1995) showed during their study on performance of two grain drills in sandy loam soil when planting wheat crop that the planting speed had significant effect on emergence rate. Guler (2005) showed that the flow rate of seed in seed drill increased as the flute diameters, the fluted roll speeds, and the active roll lengths increased. However, his tests were conducted with the aid of a test stand including a variable speed motor, speed control unit and speed monitor. Wahby et al. (2000) showed that the forward speed had significant effect on the performance of wheat grain drill. Finally, there are many factors which will affect seeding rates through seed drills, including (1) seed treatment, (2) weight of seed, (3) size of seed, (4) surface condition of seed and (5) tire configuration, pressure and slippage (www.greatplainsmfg.com/manuals/pdf/202-499b.pdf).

The main objective of the present work was to develop a simple laboratory unit for calibration and testing seed drills. However, the developed unit was checked by operating Colorado seed drill under three simulated ground wheel speeds and three inflation pressures of the ground wheel.

\section{MATERIALS AND METHODS}

\section{Structure of the developed unit:}

The developed unit for calibration and testing seed drills is composed of three parts. The first part is iron frame having two support rubber rolls covered with rubber on which the seed drill ground wheel could be move at the simulated ground speed. The second part is electric motor having speed control to get different rotational speeds. The third part is different pulleys to transfer rotational speed through motor to one of the support roll. These pulleys have different diameters as shown in Figure (1). However, Figure (2) shows the developed unit connected to electric motor. 

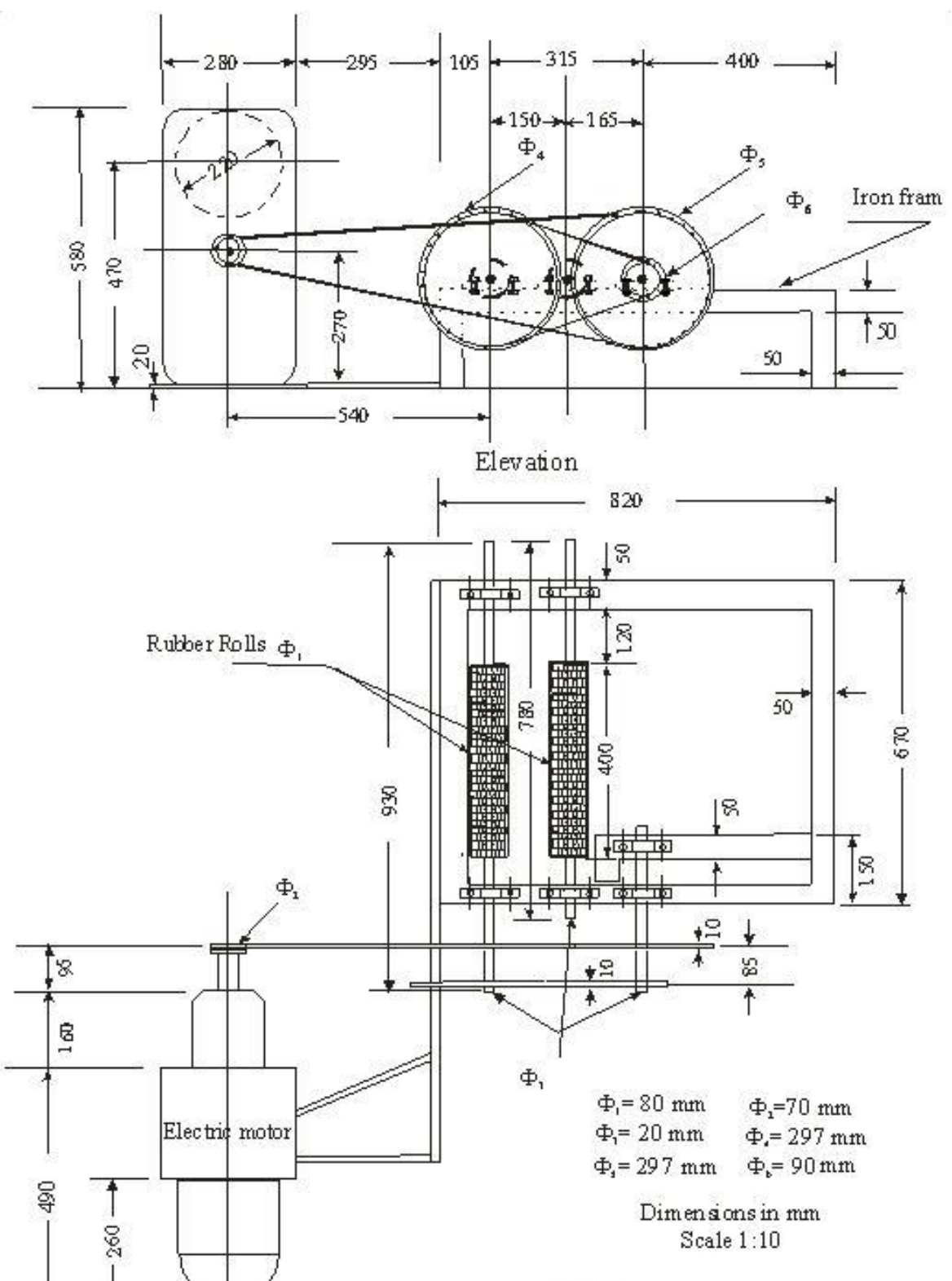

Plan

Figure (1): Elevation and plan sections of the developed unit for calibration and testing seed drills. 
Bahnasy, A. F. et al.

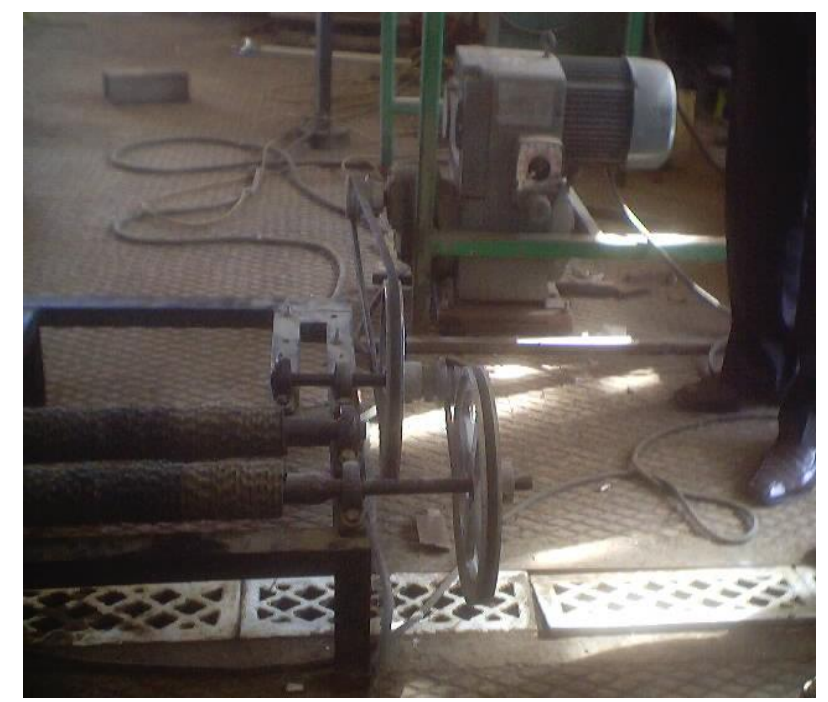

Figure (2): The developed unit connected to electric motor.

\section{Description of the seed drill under test:}

Seed drill (Colorado model) was investigated in the experiments. The drive shaft operating feed mechanism is driven by gear and pulley system through the ground wheel. The seed application rate was controlled by different ways. Whereas, the ground driving wheel transmits motion to the gearbox, and sowed distributing units. Motion passes from the wheel shaft to a pinion with 16 teeth, and from the 10 to the 60 position gear shift (seed distribution unit). Another distribution regulator could be adjusted by using a lever. This lever is positioned on the right-hand side of the machine and acts upon a 10-positione graduated sector (distribution regulator). Also, cut-off plate position could be used to control seed arrival for distribution and it had three positions 0,1 and 2 depended on types of the seeds (cut-off plate position). Colorado model had standard tires $5.00 \mathrm{SR} 15$. The ground driving wheel diameter was $64 \mathrm{~cm}$, and the perimeter was about $2 \mathrm{~m}$. The machine working width was $2.10 \mathrm{~m}$ and had 21 tubes.

\section{Instrumentation:}

Digital balance (PM 30 model) has an accuracy of $0.01 \mathrm{~g}$ with maximum capacity of $3100 \mathrm{~g}$ was used to get the weight of the seeds collecting by the plastic bags placed below the seed drill tubes. Digital stopwatch (Radio jack model) has an accuracy of $0.01 \mathrm{sec}$ with maximum capacity of $10 \mathrm{hrs}$. was used to record time. Inflation pressure gauge (Italy model) was used to record the tire inflation pressure. A $30 \mathrm{~m}$ cloth tape (Chinese model) was used to record perimeter of the ground driving wheel. Rotational speed of the ground driving wheel was recorded using speed meter (Hasler Bern model). 


\section{Treatments:}

The treatments during testing the seed drill included three different simulated ground speed and three inflation pressures. Untreated commercial wheat seeds were brought from local market with average moisture content of $14.3 \%$ d.b to be used in the tests. The main physical properties of the used wheat seeds are presented in Table (1).

Table (1): Main physical properties of the used wheat seeds.

\begin{tabular}{|c|c|l|c|c|}
\hline $\begin{array}{c}\text { Bulk density } \\
\left(\mathbf{k g} / \mathbf{m}^{3}\right)\end{array}$ & $\begin{array}{c}\text { Weight of 1000 } \\
\text { seed } \mathbf{( g )}\end{array}$ & \multicolumn{3}{|c|}{ Seed dimensions* $\mathbf{m m})$} \\
\cline { 3 - 5 } & $41.82 \pm 1.24$ & Length & $:$ & $6.24 \pm 0.27$ \\
\hline $738 \pm 38$ & & Width & $:$ & $2.46 \pm 0.14$ \\
\hline & & Thickness & $:$ & $2.21 \pm 0.12$ \\
\hline & &
\end{tabular}

* Seed dimensions shown are the averages of 100 measurement trails.

+ s.d is standard deviation.

\section{Test procedure:}

The tests were conducted with the aid of the developed unit as static test. For seed drill, the hopper was half filled with wheat seeds. The seed drill was held in the vice to free the drive wheel. Plastic bags were placed on each of the discharge tubes to collect the deposited seeds. The seed distribution unit was set at position 10, distribution regulator was set at position 2 and cutoff plate position was set at position 2 of the seed drill.

Three rotational speeds $(\mathrm{N}, \mathrm{rpm})$ of the seed drill drive wheel were achieved namely 15,25 and $40 \mathrm{rpm}$ by helping of the electric motor. So, the simulated ground wheel speed, S, could be calculated as follows:

$$
S(\mathrm{~km} / \mathrm{h})=\frac{N(\text { revolution })}{(\text { min })} \times \frac{P(\mathrm{~m})}{(\text { revolution })} \times 0.06 \ldots \ldots . .
$$

Where $P$ is the perimeter of the ground drive wheel $(\mathrm{m})$ and 0.06 is conversion unit. Table (2) indicates the corresponding simulated ground wheel speed according to different rotational speed. However, the effect of inflation pressure in the drive wheel on the perimeter of the ground drive wheel was very small.

Table (2): The obtained simulated ground wheel speeds during testing.

\begin{tabular}{|c|c|c|c|c|}
\hline $\begin{array}{c}\text { Inflation } \\
\text { pressure in the } \\
\text { drive wheel }\end{array}$ & $\begin{array}{c}\text { Perimeter of the } \\
\text { drive wheel (P) }\end{array}$ & \multicolumn{3}{|c|}{$\begin{array}{c}\text { Simulated ground wheel } \\
\text { speed (S, km/h) at different } \mathbf{~}\end{array}$} \\
\hline $\mathbf{( k P a )}$ & $\mathbf{( m )}$ & $\mathbf{1 5} \mathbf{~ r p m}$ & $\mathbf{2 5} \mathbf{~ r p m}$ & $\mathbf{4 0} \mathbf{~ r p m}$ \\
\hline 150 & 2.0 & 1.8 & 3.0 & 4.8 \\
\hline 200 & 2.0 & 1.8 & 3.0 & 4.8 \\
\hline 300 & 2.0 & 1.8 & 3.0 & 4.8 \\
\hline
\end{tabular}

Each test was completed in $90 \mathrm{sec}$. The application rate $(R, g / s)$ was calculated as follows: 


$$
R(g / s)=\frac{W}{90}
$$

Where, $\mathrm{W}$ is the total weight of the deposited wheat seeds from 21 tubes of the seed drill $(\mathrm{g})$. Each speed level was repeated at three different inflation pressure of the ground wheel. Also, coefficient of variation (CV, \%) was evaluated to reflect the sensitivity of the seed drill test. It was calculated as follows (ASAE Standards, 2004):

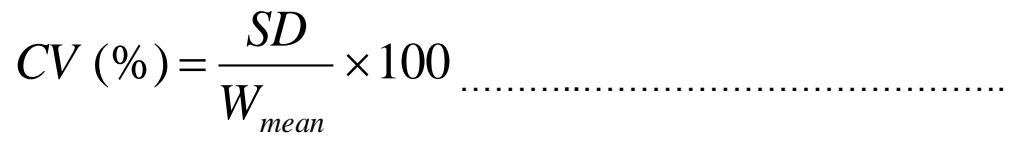

Where SD is standard deviation of deposited weight of the wheat seeds from 21 tubes of the seed drill $(\mathrm{g})$ and $W_{\text {mean }}$ is mean of weight of the wheat seeds deposited from 21 tubes of the seed drill $(\mathrm{g})$. The CV was calculated for five times and averaged to represent single treatment number.

\section{RESULTS AND DISCUSSION}

Figure (3) shows the effects of simulated ground wheel speed and ground wheel inflation pressure on the seed application rate and coefficient of variation. Meanwhile, Table (3) depicts average values of seed application rates and coefficient of variation corresponding to simulated ground wheel speeds and ground wheel inflation pressure during seed drill testing.

As shown in Table (3) increasing simulated ground wheel speed from $1.8 \mathrm{~km} / \mathrm{h}$ to $4.8 \mathrm{~km} / \mathrm{h}$ resulted in increasing in seed application rate from 37.2 $\mathrm{g} / \mathrm{s}$ to $82 \mathrm{~g} / \mathrm{s}$ at ground wheel inflation pressure of $300 \mathrm{kPa}$. Also, as illustrated in Table (3) increasing inflation pressure in the drive wheel from $150 \mathrm{kPa}$ to $300 \mathrm{kPa}$ resulted in decreasing in seed application rate from 68.9 $\mathrm{g} / \mathrm{s}$ to $54.9 \mathrm{~g} / \mathrm{s}$ at simulated ground wheel speed of $3 \mathrm{~km} / \mathrm{h}$. However, underinflated tire will make more rotations when traveling a given distance than the properly inflated tire. Therefore, the under-inflated tire will cause the metering mechanism to meter more seeds in a given distance (over-seeding). The opposite is true, for the over inflation needs fewer meters in given distance and this means under seeding rate (Hendawy, 1996).

The average of the coefficient of variation of weight of the wheat seeds deposited from 21 tubes decreased as simulated ground speed increase at any of ground wheel inflation pressure as illustrated in Figure (3). This trend may be little variation in seed weight deposited of seed drill tubes. Meanwhile, the average of the coefficient of variation of weight of the wheat seeds deposited from 21 tubes increased as ground wheel inflation pressure increasing at any of simulated ground speed as illustrated in Figure (3).

The average of the coefficient of variation of weight of the wheat seeds deposited from 21 tubes increased from $4.75 \%$ to $6.20 \%$ when ground wheel inflation pressure increasing from 150 to $300 \mathrm{kPa}$ at simulated ground speed of $4.8 \mathrm{~km} / \mathrm{h}$ as illustrated in Table (3). 

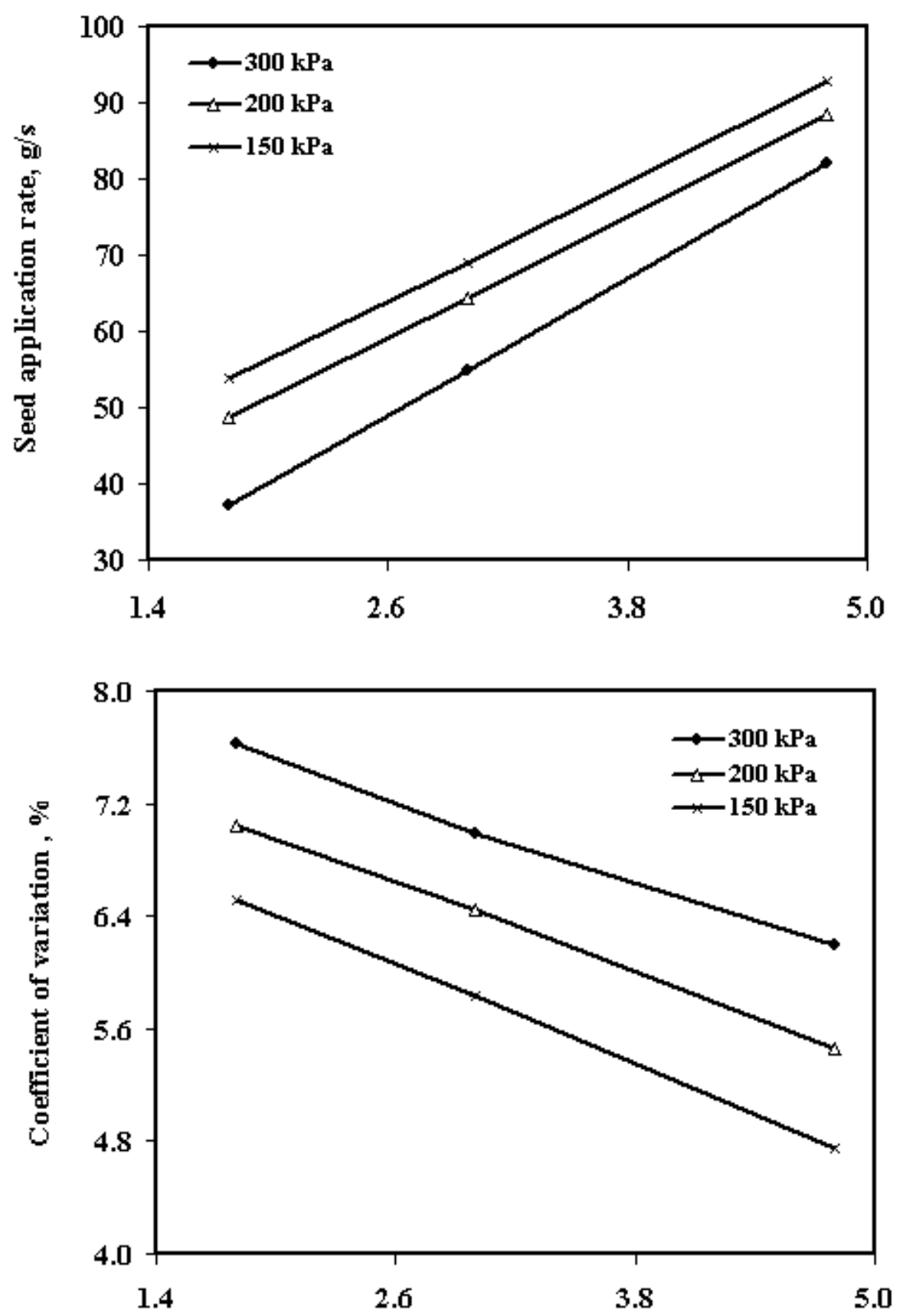

Simulated ground wheel speed, $\mathrm{km} / \mathrm{h}$

Figure (3): Effects of simulated ground wheel speed and ground wheel inflation pressure on the seed application rate and coefficient of variation. 
Bahnasy, A. F. et al.

Table (3): Average of seed application rate and coefficient of variation corresponding to different simulated ground wheel speeds and ground wheel inflation pressure during seed drill testing.

\begin{tabular}{|c|c|c|c|}
\hline $\begin{array}{c}\text { Simulated ground } \\
\text { wheel speed }\end{array}$ & $\begin{array}{c}\text { Inflation pressure in } \\
\text { the drive wheel }\end{array}$ & $\begin{array}{c}\text { Coefficient of } \\
\text { variation }\end{array}$ & $\begin{array}{c}\text { Seed } \\
\text { application rate }\end{array}$ \\
\hline $\mathbf{( k m / h )}$ & $\mathbf{( k P a )}$ & $\mathbf{( \% )}$ & $\mathbf{( g / s )}$ \\
\hline 1.8 & 150 & 6.52 & 53.8 \\
\hline 3.0 & 150 & 5.83 & 68.9 \\
\hline 4.8 & 150 & 4.75 & 92.8 \\
\hline 1.8 & 200 & 7.04 & 48.7 \\
\hline 3.0 & 200 & 6.45 & 64.3 \\
\hline 4.8 & 200 & 5.46 & 88.4 \\
\hline 1.8 & 300 & 7.63 & 37.2 \\
\hline 3.0 & 300 & 6.99 & 54.9 \\
\hline 4.8 & 300 & 6.20 & 82.0 \\
\hline
\end{tabular}

\section{CONCLUSION}

A simple laboratory unit was fabricated from available locally materials, to suit the need of the calibration and test seed drills. It was found to be suitable for these purposes. The testing results of that unit may be helpful in design and adaptation of the gear box of the seed drill. It could operate with different rotational speeds to calculate the suitable gear ratio. The relative benefit with which the unit is developed to suit the technical of knowing how of the factors affected on the imported or locally made seed drills. The average of the coefficient of variation of weight of the wheat seeds deposited from 21 tubes during checked the developed unit varied between 4.75 to $7.63 \%$.

\section{REFERENCES}

ASAE standards, 51st ed. S386.2 (2004). Calibration and distribution pattern testing of agricultural aerial application equipment. St. Joseph, Mich.: ASAE.

Babeir, A.S. and S.A. Al Suhaibani (1995). Performance of two grain drills in sandy loam soil when planting wheat crop. Journal of King Saud Univ., Vol. 7, Agricultural Science (1):155-164 (In Arabic).

Boydas, M. G. and N. Turgut (2007). Effect of vibration, roller design, and seed rates on the seed flow evenness of a studded feed roller. Applied Engineering in Agriculture, 23(4): 413-418.

Ess, D. R., S. E. Hawkins, J. C. Young and E. P. Christmas (2005). Evaluation of the performance of a belt metering system for soybeans planted with a grain drill. Applied Engineering in Agriculture, 21(6): 965969.

Guler, I. E. (2005). Effects of flute diameter, fluted roll length, and speed on alfalfa seed flow. Applied Engineering in Agriculture, 21(1): 5-7. 
Hendawy, N.A. (1996). Factors affecting seed drilling rate. Misr J. Ag. Eng., $13(1): 202-210$.

Kepner, R. A., R. Bainer and E. L. Barger (1980). Principles of farm machinery, Third Edition. Westport, Conn.: AVI Publishing Company, Inc.

$\mathrm{Li}, \mathrm{W}$. and J. Lin (2006). Seeding precision test based on machine vision. Computers in Agriculture and Natural Resources, 4th World Congress Conference, Proceedings of the 24-26 July 2006, Orlando, Florida, USA: $375-380$.

Nielsen, R. L. (1995). Planting speed effects on stand establishment and grain yield of corn. J. Prod. Agric., 8 (3): 391-393.

PAMI (Prairie Agricultural Machinery Institute) (1978). Evaluation report 42 Massey Ferguson 63 grain drill. http://www.agric.gov.ab.ca/navigation/engineering.

Raheman, H. and U. Singh (2003). A sensor for seed slow from seed metering mechanisms. IE (I) Journal AG, Vol. 84:6-8.

Siemens, M. C., T. J. Darnell and D. E. Hulick (2007). Performance of two hoe-type air drills sowing green peas in a conservation tillage system. Applied Engineering in Agriculture, 23 (1): 23-29.

Wahby, F., A. Al-Janobi and A.M. Aboukarima (2000). Performance of wheat grain drill using different covering methods. Emir. J. Agric. Sci., 12:6079 (In Arabic).

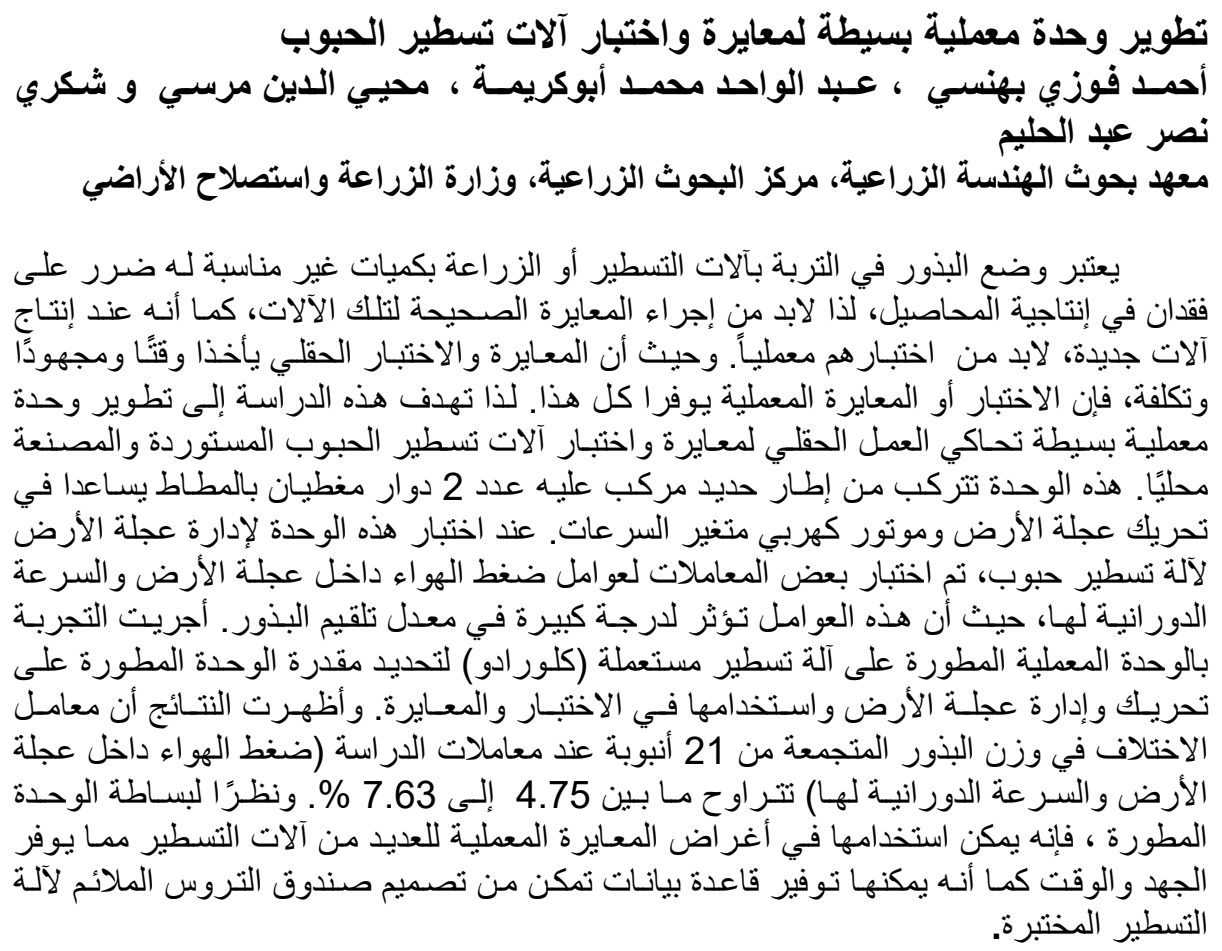

